\title{
A NOVEL FUZZY MCDM MODEL FOR INVENTORY MANAGEMENT IN ORDER TO INCREASE BUSINESS EFFICIENCY
}

\author{
Dragan VUKASOVIĆ ${ }^{1}$, Dejan GLIGOVIĆ ${ }^{2}$, Svetlana TERZIĆ ${ }^{3}$, \\ Željko STEVIĆ ${ }^{1}{ }^{*}$, Perica MACURA ${ }^{4}$ \\ ${ }^{1}$ Faculty of Economics, Independent University of Banja Luka, Banja Luka, \\ Bosnia and Herzegovina \\ ${ }^{2}$ Modern Business School, Belgrade, Serbia \\ ${ }^{3}$ Faculty of Transport and Traffic Engineering, University of East Sarajevo, Doboj, \\ Bosnia and Herzegovina \\ ${ }^{4}$ Faculty of Economics, University of Banja Luka, Banja Luka, Bosnia and Herzegovina
}

Received 25 November 2020; accepted 29 January 2021

\begin{abstract}
Appropriate implementation and organization of logistics activities greatly contributes to the creation of a better business environment in companies. This is reflected in increased business efficiency, cost rationalization, increased productivity and better overall quality. In order for a company to achieve sustainability of its business and its competitiveness, the link between the marketing logistics system and other logistics subsystems is particularly evident. Thereby, it is necessary to lead proactive management with a focus on key resources. In this paper, two novel integrated models in fuzzy form have been created. The first model includes the integration of the fuzzy Full Consistency Method (fuzzy FUCOM) and the fuzzy Evaluation based on Distance from Average Solution (EDAS) method for sorting 78 products regarding the following four criteria: quantity, unit price, annual procurement costs and demand. The second model involves the integration of the fuzzy FUCOM method and ABC analysis for the purpose of inventory sorting considering different significance of criteria. A range of values has been formed for each product category within the fuzzy FUCOM and fuzzy EDAS models, on the basis of which their sorting has been performed. The advantages and verification of the developed integrated fuzzy models have been performed through comparison with former traditional approaches. It has been determined based on an extensive sensitivity analysis that the developed models have better performance compared to the existing ones.
\end{abstract}

Keywords: inventory management, business efficiency, annual procurement costs, fuzzy FUCOM, fuzzy EDAS, ABC analysis.

JEL Classification: C44, D81, M21, M31.

*Corresponding author. E-mails: zeljkostevic88@yahoo.com; zeljko.stevic@sf.ues.rs.ba

Copyright @ 2021 The Author(s). Published by Vilnius Gediminas Technical University

This is an Open Access article distributed under the terms of the Creative Commons Attribution License (http://creativecommons. $\mathrm{org} / \mathrm{licenses} / \mathrm{by} / 4.0 /$ ), which permits unrestricted use, distribution, and reproduction in any medium, provided the original author and source are credited. 


\section{Introduction}

Logistics market according to Keller and Kotler (2006) includes planning the infrastructure to meet demand, then implementing and controlling the physical flows of materials and final products to meet customer requirements while making a profit. Increasing business efficiency through cost rationalization and more economical use of all resources has become imperative in every company in order to create the best possible basis for its management. Today's competitiveness, observing the global market, is at a high competition level, so it is very difficult to manage logistics activities in the right way, especially those related to financial flows. Since according to Anthony et al. (2019), inventory management ratios have a significant share in financial performance, it is necessary to reduce costs through all logistics activities related to inventories. To achieve competitiveness is possible if the costs of internal logistics activities are reduced, as evidenced by Stević et al. (2018a) who emphasize the necessity of rationalization of logistics resources.

Given the impossibility of creating a just-in-time concept, stock-keeping is present on a daily basis, whether it is a manufacturing or trading business. Accordingly, it is necessary to create appropriate models for inventory classification and management. Optimal management of business resources and processes requires a proactive way of managing and focusing on key economic parameters. The importance of managing these systems can be seen from the paper (ten Hompel \& Schmidt, 2008) in which it is stated that storage systems and material handling are the most important parts of goods flows since they link production and consumption points. Considering the above, it can be concluded that the most important thing is to establish efficient synchronization of warehousing activities, and this primarily refers to inventory management. The essence of control over inventories, and thus over the allocation of funds in that part of short-term assets, is to maintain inventories at an optimal level.

Several goals can be set through the research. The first goal involves creating a novel fuzzy Multi-Criteria Decision-Making (MCDM) model consisting of the fuzzy FUCOM and fuzzy EDAS methods. The integration of these methods contributes to the field of treating multicriteria approaches. Additionally, the developed approach enriches the field of inventory sorting because the developed fuzzy model is verified in the area of multi-criteria inventory classification. Another goal is to create an integrated fuzzy FUCOM - ABC model, also applied in the same field. This model involves performing ABC analysis with four criteria whose weights are determined by the fuzzy FUCOM method. The third goal of the paper is to increase business efficiency by rationalizing costs in inventory management. It is manifested through sorting inventory into certain groups and the possibility of creating adequate marketing logistics policies. The significance of this research and the defined goals can be seen through the fact that the consideration of such a model in the literature is a rarity. Apart from this, through described goals can be noticed novelty of this study that represents the main contributions. The inventory management system according to van den Berg and Zijm (1999) is one of the most important issues in logistics companies, i.e. their warehousing systems. It is for this reason that such models that strive for intelligent inventory management through increased business efficiency and reduced logistics costs have been formed in the paper.

The rest of the paper is presented through four sections. In Section 1, a review of previous studies with similar issues is performed. The second section of the paper refers to materials 
and methods presenting primarily the flow of the research. Within the proposed methodology, a detailed overview of all used methods is given, as well as a description of a case study with defined inputs. Section 3 involves the presentation of results with individual steps of the calculation. The fourth section of the study refers to the verification of the developed integrated fuzzy models through comparison with traditional approaches to inventory management, i.e. inventory sorting. The last section briefly summarizes the results and contributions of the paper with guidelines for the continuation of research.

\section{Background}

Inventory management according to Božić and Aćimović (2014) can be defined as a strategic function of the company and as one of the most important segments of operational management. Today, many companies face certain problems that can significantly impede the optimality of inventory management due to uncertain deliveries. Therefore, it is necessary to form appropriate models of inventory classification as a prerequisite for their optimal management. The most common analysis involves classifying materials or products into three groups: A - represents very important items, B - represents moderately important items and C - represents relatively irrelevant items (Kubasakova et al., 2015; Douissa \& Jabeur, 2016; Erceg et al., 2019). The purpose of applying this classification is to establish an effective system in order to achieve greater cost-effectiveness and business success. This is also confirmed by Liu et al. (2016) who state that such a classification has a significant impact on the structure of total inventory costs, and their rationalization (Oliveira \& Vaz, 2017). The classical $\mathrm{ABC}$ analysis that takes into account only one criterion can be said that due to its simplicity is the most widely used analysis in determining the state of stocks. However, the biggest disadvantage of classical ABC analysis is the acceptance of the single-criterion function, so there are significant papers in the literature that take into account several criteria. This is confirmed by Chu et al. (2008) according to whom one of the most important improvements of $\mathrm{ABC}$ analysis includes the possibility of considering different classification criteria. The study (Flores \& Whybark, 1986) can be pointed out as the beginning of the consideration of multi-criteria function and integration with MCDM models. In their later studies, the same authors strived for the greatest possible application of multi-criteria optimization, emphasizing the importance of MCDM methods. One of significant studies is (Ishizaka et al., 2018), in which the sorting of inventory is performed considering the following criteria: Annual Usage Value (AUV), Frequency of Issue per year (FOI), Current Stock Value (CSV). It has been concluded that in comparison with a classical analysis, this model achieves significant savings. Mallick et al. (2019) in their conducted research have performed ABC analysis based on four criteria: UP, Annual Consumption Cost, Annual Consumption Rate, and Average Inventory Cost. They have implemented the modified similarity-based method for the ABC analysis.

The research (Hanafi et al., 2019) determined necessary items for the execution of the economic order quantity by applying the ABC analysis. Cherif and Ladhari (2016) created a hybrid model consisting of $\mathrm{ABC}$ classification using an evolutionary algorithm and the MCDM method. This research minimizes inventory management costs and ensures acceptable performance. A model that integrates different MCDM methods and ABC analysis was performed in (Arikan \& Citak, 2017) for the needs of an electronic enterprise. In a paper 
published by Erceg et al. (2019), it has been formed a multi-criteria model of inventory management in the storage system and cost rationalization related to activities and processes in the storage system. Several techniques have been used to obtain a model that provides good results and helps run an efficient business. At first, the products were classified according to $\mathrm{ABC}$ analysis, based on data collected on an annual basis. Then, a list of potential suppliers was formed for each group and the criteria to be used to evaluate alternatives were determined. Eraslan and İÇ (2020) have developed Improved Decision Support System (IDSS) as tool which can help in decision-making related to inventory classification. They have used two MCDM methods: AHP and ANP in combination with other approaches. The main task that has been performed in their study decreasing the total time for inventory classification. Combination of Entropy, TOPSIS (the technique for order preference by similarity to ideal solution), and goal programming have performed in (Kheybari et al., 2019) in order to make $\mathrm{ABC}$ analysis in a proper and quality way. In study (Kartal et al., 2016) have been developed a hybrid model consisting of the integration of machine learning and MCDM method for effectively conducting inventory analysis. Considering more than one criterion in ABC analysis became strategic needs as have mentioned by Ishizaka and Gordon (2017) in their study. They have proposed a new methodology MACBETHSort for sorting products in groups $\mathrm{A}, \mathrm{B}$, and $\mathrm{C}$.

From the review of studies, as well as papers (Douissa \& Jabeur, 2020; Abdolazimi et al., 2020), it can be seen that quantitative and value analysis is most frequently used as a criterion. When applying $\mathrm{ABC}$ analysis based on a multi-criteria function, two problems can arise: how to select relevant criteria and how to determine their significance. The proposed fuzzy MCDM model solves the stated problems. As another motive for creating this model, it can be singled out the fact that the crisp EDAS method (Keshavarz Ghorabaee et al., 2015) was created exactly for the purposes of multi-criteria inventory classification. Taking into account the above, it can be concluded that $\mathrm{ABC}$ analysis is almost an indispensable tool in the formation of inventory management models, but it is important to point out that in itself is not enough. The authors of the paper (Arikan \& Citak, 2017) also confirm the stated above, considering the importance of this analysis, on the one hand, and the lack of taking into account only one criterion, on the other hand. Thereby, it is necessary to develop various multiphase integrated models in terms of differences of a specific case.

\section{Materials and methods}

Figure 1 shows the applied methodology in the paper. The overall flow of research can be divided into four steps, and each of them consists of several activities.

The total number of steps in the proposed methodology is four, consisting of several activities each, which makes a total of 11 activities. The following section of the paper describes in detail all the steps with the presented methods that are applied.

\subsection{The first step - defining inputs}

In the first step, the criteria for inventory management are first defined considering all important parameters that have economic appropriateness and contribute to the optimization 


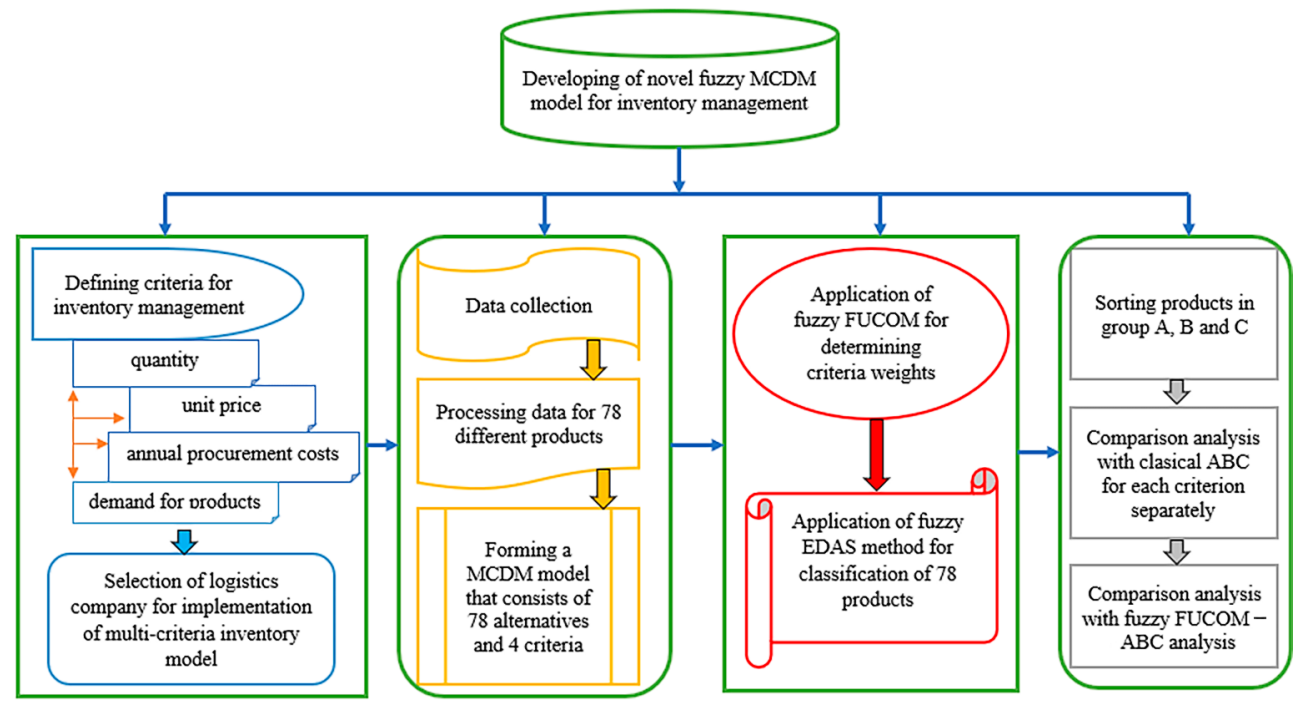

Figure 1. Research flow for inventory management

of the logistics system. A total of four criteria have been defined: quantity, unit price, annual procurement costs and demand for products. Quantity is the amount ordered on an annual basis and can be expressed in the following measuring units: pieces, bags, tons, square meters. The unit price is an individual monetary expression of the cost of aforementioned products. When the multiplication of the second criterion (unit price) is performed for each product individually with the quantity of a certain product, the third criterion (annual procurement costs) is obtained. The fourth criterion is defined as the demand for products, which includes observing the annual level and the percentage of products ended up on the market compared to the total quantity in stock. After that, the company in which the research is to be conducted is defined. The logistics company that is the subject of the research was founded in 1997 and is located on the territory of Bosnia and Herzegovina. According to the classification, it is a medium-sized company that covers an area of 5.000 square meters. The main activity of the company is of a commercial nature, but lately they have been investing additionally in their own manufacture. Regarding means of transport and handling, the company owns four large trucks, two of which have a crane by which they unload material from the truck, three smaller trucks with a closed trailer, two vans and two forklifts. They also possess a manual low-floor forklift that is used for internal transport of goods. When it comes to storage systems, they have their own closed-type warehouse of 1120 square meters. In addition to the closed warehouse, there is also an open warehouse for goods that do not change their properties under various weather conditions.

\subsection{The second step - data collection and processing}

The activities related to this step include data collection, their processing and the formation of a fuzzy multi-criteria model. Data collection was performed on the basis of several visits to the logistics company, interviews with managers, and insight into a detailed report on pro- 
curement and sales (marketing logistics) for the previous year. After that, the collected data were processed, and it was determined that there were a total of 78 different products that were the subject of marketing logistics. The collected data cover the whole period of 2019 . Product characteristics were systematized by: product code, quantity of purchased products, purchase value per unit of product, total value of purchase by products and demand. As a third activity, the formation of the fuzzy MCDM model, which includes 78 alternatives and four criteria, was performed.

\subsection{The third step - forming and application of integrated fuzzy MCDM model}

As the third step of the proposed research methodology, it stands out one of the largest contributions of the paper, which includes the integration of the fuzzy FUCOM (Pamučar \& Ecer, 2020; Pamučar et al., 2020) and fuzzy EDAS (Keshavarz Ghorabaee et al., 2016; Stević et al., 2018b) methods. Using the Fuzzy FUCOM method, the significance of criteria is determined through the quantification of their values. The algorithm of this method is given in the following section.

\subsubsection{Fuzzy FUCOM method}

Step 1. Defining a set of criteria.

Step 2. Determining the ranking of criteria based on experts' preferences according to the importance of the criteria:

$$
\bar{C}_{j(1)}>\bar{C}_{j(2)}>\ldots>\bar{C}_{j(k)} .
$$

Step 3. Comparisons of the criteria - fuzzy comparative significance $\bar{\varphi}_{k /(k+1)}$ is determined by applying Equation (2):

$$
\bar{\varphi}_{k /(k+1)}=\frac{\bar{\varpi}_{C_{j(k)}}}{\bar{\varpi}_{C_{j(k+1)}}}=\frac{\left(\varpi_{C_{j(k)}}^{l}, \varpi_{C_{j(k)}}^{m}, \varpi_{C_{j(k)}}^{u}\right)}{\left(\varpi_{C_{j(k+1)}}^{l}, \varpi_{C_{j(k+1)}}^{m}, \varpi_{C_{j(k+1)}^{u}}^{u}\right)},
$$

Thus, a fuzzy vector of comparative significance of evaluation criteria is obtained, Equation (3):

$$
\bar{\Phi}=\left(\bar{\varphi}_{1 / 2}, \bar{\varphi}_{2 / 3}, \ldots, \bar{\varphi}_{k /(k+1)}\right),
$$

where $\bar{\varphi}_{k /(k+1)}$ represents the significance of the criterion of $\bar{C}_{j(k)}$ rank compared to the criterion of $\bar{C}_{j(k+1)}$ rank.

Step 4. Calculation of the optimal fuzzy weights that should satisfy the conditions defined by Equations (4) and (5):

$$
\begin{aligned}
& \frac{\bar{w}_{k}}{\bar{w}_{k+1}}=\bar{\varphi}_{k /(k+1)} ; \\
& \frac{\bar{w}_{k}}{\bar{w}_{k+2}}=\bar{\varphi}_{k /(k+1)} \otimes \bar{\varphi}_{(k+1) /(k+2)} .
\end{aligned}
$$

where $\bar{\varphi}_{k /(k+1)}$ represents the comparative significance of the criteria $\bar{C}_{j(k)}$ and $\bar{C}_{j(k+1)}$ Based on the previous equations, it can be set the final nonlinear model for calculating the optimal fuzzy values of the weight coefficients of evaluation criteria $\left(\bar{w}_{1}, \bar{w}_{2}, \ldots, \bar{w}_{n}\right)^{T}$ : 


$$
\begin{aligned}
& \min \chi \\
& \left\{\begin{array}{l}
\left|\frac{\bar{w}_{k}}{\bar{w}_{k+1}}-\bar{\varphi}_{k /(k+1)}\right| \leq \chi, \forall j, \quad\left|\frac{\bar{w}_{k}}{\bar{w}_{k+2}}-\bar{\varphi}_{k /(k+1)} \otimes \bar{\varphi}_{(k+1) /(k+2)}\right| \leq \chi, \forall j \\
\sum_{j=1}^{n} \bar{w}_{j}=1, \quad w_{j}^{l} \leq w_{j}^{m} \leq w_{j}^{u}, \quad w_{j}^{l} \geq 0, \forall j, \quad j=1,2, \ldots, n
\end{array},\right.
\end{aligned}
$$

where $\bar{w}_{j}=\left(w_{j}^{l}, w_{j}^{m}, w_{j}^{u}\right)$ and $\bar{\varphi}_{k /(k+1)}=\left(\varphi_{k /(k+1)}^{l}, \varphi_{k /(k+1)}^{m}, \varphi_{k /(k+1)}^{u}\right)$.

\subsubsection{Fuzzy EDAS method}

Step 1: Forming the average decision matrix $(\mathrm{X})$ :

$$
\begin{aligned}
& X=\left[\bar{x}_{i j}\right]_{n x m} ; \\
& \bar{x}_{i j}=\frac{1}{k} \oplus_{p=1}^{k} \bar{x}_{i j}^{p},
\end{aligned}
$$

where $\bar{x}_{i j}^{p}$ denotes the performance value of alternative $A_{i}=(1 \leq i \leq n)$ with respect to criterion $c_{j}=(1 \leq j \leq m)$ assigned by the $p$ th decision-maker $(1 \leq p \leq k)$.

Step 2: In this step, in the original method, the weights of the criteria are formed by applying the averaging of experts' preferences. Since the fuzzy FUCOM method used to obtain the criterion weights has been previously described in this paper, there is no need for this step from the original fuzzy EDAS method.

Step 3: Forming the matrix of average solutions:

$$
\begin{aligned}
& A V=\left[\overline{a v}_{j}\right]_{1 \times m} ; \\
& \overline{a v}_{j}=\frac{1}{n} \oplus_{i=1}^{n} \bar{x}_{i j},
\end{aligned}
$$

where $\overline{a v}_{j}$ represents the average solutions with respect to each criterion.

Step 4: Positive distance from average (PDA) and negative distance from average (NDA) solution should be obtained using Equations (11) and (12) respecting a type of criteria (benefit or cost):

$$
\begin{gathered}
P D A=\left[\overline{p d a}_{i j}\right]_{n \times m} \Rightarrow \overline{p d a}_{i j}=\left\{\begin{array}{ll}
\frac{\psi\left(\bar{x}_{i j}-\overline{a v}_{j}\right)}{k\left(\overline{a v}_{j}\right)} & \text { if } j \in B \\
\frac{\psi\left(\overline{a v}_{j}-\bar{x}_{i j}\right)}{k\left(\overline{a v}_{j}\right)} & \text { if } j \in C
\end{array} ;\right. \\
N D A=\left[\overline{n d a}_{i j}\right]_{n \times m} \Rightarrow \overline{n d a}_{i j}= \begin{cases}\frac{\psi\left(\overline{a v}_{j}-\bar{x}_{i j}\right)}{k\left(\overline{a v}_{j}\right)} & \text { if } j \in B \\
\frac{\psi\left(\bar{x}_{i j}-\overline{a v}_{j}\right)}{k\left(\overline{a v}_{j}\right)} & \text { if } j \in C\end{cases}
\end{gathered}
$$


Step 5: Obtaining the weighted sum of positive and negative distances for all alternatives:

$$
\begin{aligned}
& \overline{s p}_{i}=\bigoplus_{i=1}^{m}\left(\bar{w}_{j} \otimes \overline{p d a}_{i j}\right) ; \\
& \overline{s n}_{i}=\bigoplus_{i=1}^{m}\left(\bar{w}_{j} \otimes \overline{n d a}_{i j}\right) .
\end{aligned}
$$

Step 6: The normalization of $\overline{s p}_{i}$ and $\overline{s n}_{i}$ values for all alternatives:

$$
\begin{aligned}
& {\overline{n s p_{i}}}=\frac{\overline{s p}_{i}}{\max \left(k\left(\overline{s p}_{i}\right)\right)} ; \\
& {\overline{n s n_{i}}}=\frac{\overline{s n}_{i}}{\max \left(k\left(\overline{s n}_{i}\right)\right)} .
\end{aligned}
$$

Step 7: Determination of the appraisal score $\left(\widetilde{a s}_{i}\right)$ for all alternatives:

$$
\overline{a s}_{i}=\frac{1}{2}\left(\overline{n s p}_{i} \otimes{\overline{n s n_{i}}}\right) \text {. }
$$

Step 8: Ranking the alternatives according to the decreasing values of appraisal scores.

\subsection{The fourth step - results and sensitivity analysis}

In the fourth step, the results and sensitivity analysis through three activities are presented. Primarily, based on the obtained results, the products are sorted by groups A, B and C, taking into account different ranges of results and the basic settings of $\mathrm{ABC}$ analysis presented in the following section of the paper.

\subsubsection{ABC analysis}

$\mathrm{ABC}$ analysis in inventory management is an almost indispensable tool since efficient inventory classification can be a vital activity for companies, especially when it comes to a large amount of inventory. ABC analysis is a simple stochastic method. The goal of this analysis is the possibility of achieving the highest possible economy and productivity, and thus increasing efficiency and economy of business. It is particularly suitable for usage in companies that have a diverse range of products, as is the case in this study. One of the primary purposes of applying this analysis is to establish a functional control and management system within marketing logistics and inventory management. $\mathrm{ABC}$ analysis is based on the most important products that are of the greatest benefit. The percentage of costs of individual product categories in relation to the total procurement costs should satisfy the condition shown by Equation (18):

$$
A=40-80 \%, B=15-41 \%, C=5-20 \% .
$$

The percentage of the number of individual product categories out of the total number of all product types should satisfy the condition shown by Equation (19):

$$
A=5-25 \%, B=20-40 \%, C=40-75 \% .
$$

The 3 rd condition shows the relation of the number of products by the category $A<B<C$. 


\subsubsection{Comparison analysis}

In the last two activities of the fourth step of the developed methodology, the obtained results are compared with the classical $\mathrm{ABC}$ analysis and with the novel integrated fuzzy FUCOM$\mathrm{ABC}$ model. When it comes to the comparison with the classical method, it is based on the comparison of obtained results with the results of single-criterion $\mathrm{ABC}$ analysis. Each of the four criteria is observed individually and $\mathrm{ABC}$ analysis is created. A novel integrated fuzzy FUCOM-ABC, which takes into account the different significance of criteria, has shown good characteristics, but slightly worse than the developed fuzzy FUCOM-fuzzy EDAS in terms of a specific case.

\section{Results - application of developed integrated fuzzy MCDM model to inventory management}

This section presents the results of the research referring to individual steps of the calculation in the proposed methodology. Based on the implementation of the first two steps of the previously described methodology, the calculation of the weights of the criteria is approached first, and then the classification of products. The calculation of criterion weights using the FUCOM method is performed as follows. The first step of this method is the formation of a set of criteria, which is performed in the first step of the developed methodology and explained in Section 2.1. After that, they are ranked according to the assumed significance by managers in the company. The ranking of the criteria in the second step is as follows: $\mathrm{C} 3>$ $\mathrm{C} 4>\mathrm{C} 1>\mathrm{C} 2$. The comparison of the criteria is shown in Table 1.

Table 1. Fuzzy assessment of the criteria for classification of products

\begin{tabular}{|c|c|c|c|c|}
\hline Criteria & $\mathrm{C} 3$ & $\mathrm{C} 4$ & $\mathrm{C} 1$ & $\mathrm{C} 2$ \\
\hline & $(1.00,1.00,1.00)$ & $(1.10,1.20,1.30)$ & $(1.30,1.40,1.50)$ & $(1.50,1.60,1.70)$ \\
\hline
\end{tabular}

By applying Expression (4), the comparative significance of the criteria is defined:

$$
\begin{aligned}
& \bar{\varphi}_{C 3 / C 4}=\bar{\varpi}_{C 3} / \bar{\varpi}_{C 4}=(1.10,1.20,1.30) /(1.00,1.00,1.00)=(1.10,1.20,1.30) ; \\
& \bar{\varphi}_{C 4 / C 1}=\bar{\varpi}_{C 1} / \bar{\varpi}_{C 4}=(1.30,1.40,1.50) /(1.30,1.20,1.10)=(1.00,1.17,1.36) ; \\
& \bar{\varphi}_{C 1 / C 2}=\bar{\varpi}_{C 2} / \bar{\varpi}_{C 1}=(1.50,1.60,1.70) /(1.30,1.40,1.50)=(1.00,1.14,1.31) .
\end{aligned}
$$

The values obtained by comparison represent the first limitation of the model. After that, applying Equation (5) in the following way, another limitation of the model is obtained.

$$
\begin{aligned}
& \bar{w}_{C 3} / \bar{w}_{C 1}=(1.10,1.20,1.30) \otimes(1.00,1.17,1.36)=(1.10,1.40,1.77) ; \\
& \bar{w}_{C 4} / \bar{w}_{C 2}=(1.00,1.17,1.36) \otimes(1.00,1.14,1.31)=(1.00,1.33,1.78) .
\end{aligned}
$$

Then, a model defined by Equation (6) is set up and solved in the Lingo program to obtain fuzzy values of the criteria: 
$\min \chi$

$$
\left\{\begin{array}{l}
\left(\frac{w_{3}^{l}}{w_{4}^{u}}-1.10\right) \leq \chi ;\left(\frac{w_{3}^{m}}{w_{4}^{m}}-1.20\right) \leq \chi ;\left(\frac{w_{3}^{u}}{w_{4}^{l}}-1.30\right) \leq \chi ;\left(\frac{w_{4}^{l}}{w_{1}^{u}}-1.00\right) \leq \chi ;\left(\frac{w_{4}^{m}}{w_{1}^{m}}-1.17\right) \leq \chi ;\left(\frac{w_{4}^{u}}{w_{1}^{l}}-1.36\right) \leq \chi ; \\
\left(\frac{w_{1}^{l}}{w_{2}^{u}}-1.00\right) \leq \chi ;\left(\frac{w_{1}^{m}}{w_{2}^{m}}-1.14\right) \leq \chi ;\left(\frac{w_{1}^{u}}{w_{3}^{l}}-1.31\right) \leq \chi ;\left(\frac{w_{3}^{l}}{w_{1}^{u}}-1.10\right) \leq \chi ;\left(\frac{w_{3}^{m}}{w_{1}^{m}}-1.40\right) \leq \chi ;\left(\frac{w_{3}^{u}}{w_{1}^{l}}-1.77\right) \leq \chi ; \\
\left(\frac{w_{4}^{l}}{w_{2}^{u}}-1.00\right) \leq \chi ;\left(\frac{w_{4}^{m}}{w_{2}^{m}}-1.33\right) \leq \chi ;\left(\frac{w_{4}^{u}}{w_{2}^{l}}-1.78\right) \leq \chi ;\left(w_{1}^{l}+4 \cdot w_{1}^{m}+w_{1}^{u}\right) / 6+\left(w_{2}^{l}+4 \cdot w_{2}^{m}+w_{2}^{u}\right) / 6+ \\
\left(w_{3}^{l}+4 \cdot w_{3}^{m}+w_{3}^{u}\right) / 6+\left(w_{4}^{l}+4 \cdot w_{4}^{m}+w_{4}^{u}\right) / 6=1 ; \\
w_{1}^{l} \leq w_{1}^{m} \leq w_{1}^{u} ; w_{2}^{l} \leq w_{2}^{m} \leq w_{2}^{u} ; w_{3}^{l} \leq w_{3}^{m} \leq w_{3}^{u} ; \\
w_{4}^{l} \leq w_{4}^{m} \leq w_{4}^{u} ; w_{1}^{l}, w_{2}^{l}, w_{3}^{l}, w_{4}^{l} \geq 0 .
\end{array}\right.
$$

By solving this model, the fuzzy values of the criteria are obtained, $\bar{w}_{j}=((0.201,0.226,0.239)$, $(0.170,0.183,0.223),(0.287,0.333,0.336),(0.245,0.261,0.286))^{T}$ and $\chi=0.10$. By applying defuzzification, crisp values are obtained: $w_{1}=0.224, w_{2}=0.188, w_{3}=0.326, w_{4}=0.263$. After determining the weights of the criteria using the fuzzy FUCOM method, the calculation with the fuzzy EDAS methodology is further approached. First, an initial matrix with linguistic values is created (Table 2), after which the transformation into trapezoidal fuzzy numbers is performed in order to be able to classify inventory.

Then, the transformation into fuzzy trapezoidal numbers and the calculation of the matrix of average values are performed. Applying Equation (11), a PDA matrix is formed, and applying Equation (12), an NDA matrix is obtained. It is important to note that all criteria in the model are set as criteria that belong to the benefit group because the classification of inventory is performed on the basis of maximization. To obtain the final results shown partly in Table 3, the fifth step of the fuzzy EDAS method should be applied, which is the

\begin{tabular}{|c|c|c|c|c|c|c|c|c|c|c|c|c|c|}
\hline & $\mathrm{A} 1$ & A2 & A3 & $\mathrm{A} 4$ & A5 & A6 & A7 & A8 & A9 & A 10 & A11 & A12 & A 13 \\
\hline $\mathrm{C} 1$ & $\mathrm{~L}$ & $\mathrm{VL}$ & $\mathrm{L}$ & $\mathrm{VL}$ & $\mathrm{VL}$ & $M$ & $\mathrm{VL}$ & $\mathrm{ML}$ & $\mathrm{L}$ & $\mathrm{VL}$ & $\mathrm{MH}$ & ML & $\mathrm{VL}$ \\
\hline $\mathrm{C} 2$ & ML & $\mathrm{M}$ & $\mathrm{H}$ & $\mathrm{VH}$ & ML & ML & ML & $M$ & $\mathrm{VH}$ & $\mathrm{H}$ & ML & $\mathrm{VH}$ & $\mathrm{MH}$ \\
\hline C3 & ML & ML & $\mathrm{M}$ & $\mathrm{MH}$ & ML & ML & $\mathrm{VL}$ & ML & $\mathrm{VH}$ & $\mathrm{M}$ & $\mathrm{MH}$ & $\mathrm{VH}$ & $\mathrm{ML}$ \\
\hline $\mathrm{C} 4$ & $\mathrm{H}$ & $\mathrm{VH}$ & $\mathrm{H}$ & $\mathrm{M}$ & $\mathrm{H}$ & $\mathrm{H}$ & $\mathrm{H}$ & $\mathrm{H}$ & $\mathrm{VH}$ & $\mathrm{MH}$ & $\mathrm{VH}$ & $\mathrm{H}$ & $\mathrm{H}$ \\
\hline \\
\hline & A66 & A67 & A68 & A69 & A70 & A71 & A72 & A73 & A74 & A75 & A76 & A77 & A78 \\
\hline $\mathrm{C} 1$ & $\mathrm{~L}$ & $\mathrm{VL}$ & $\mathrm{H}$ & $M$ & $\mathrm{VL}$ & $\mathrm{VL}$ & ML & VL & ML & $\mathrm{L}$ & $\mathrm{L}$ & $\mathrm{VL}$ & $\mathrm{VL}$ \\
\hline $\mathrm{C} 2$ & $M$ & $\mathrm{M}$ & $\mathrm{ML}$ & $\mathrm{L}$ & $\mathrm{MH}$ & $\mathrm{ML}$ & $M$ & ML & $M$ & $M$ & $M$ & $M$ & $\mathrm{M}$ \\
\hline C3 & $\mathrm{ML}$ & ML & $\mathrm{VH}$ & ML & ML & $\mathrm{L}$ & $\mathrm{M}$ & ML & $\mathrm{M}$ & $\mathrm{ML}$ & ML & ML & ML \\
\hline $\mathrm{C} 4$ & $\mathrm{MH}$ & $\mathrm{H}$ & $\mathrm{H}$ & $\mathrm{MH}$ & $\mathrm{VH}$ & $\mathrm{H}$ & $\mathrm{MH}$ & $\mathrm{H}$ & $\mathrm{VH}$ & $\mathrm{H}$ & $\mathrm{MH}$ & $\mathrm{MH}$ & $\mathrm{H}$ \\
\hline
\end{tabular}
sum of the weighted matrices for positive $\widetilde{s p_{i}}$ and negative distance $\widetilde{s n_{i}}$ for all inventory items. After that, in the sixth step, the values from the previous matrices, $\widetilde{n s p_{i}}$ and $\widetilde{n s n_{i}}$, are normalized. In the last two steps, an appraisal score $\left(\widetilde{a s_{i}}\right)$ and defuzzification appraisal score $\left(\widetilde{a s}_{i}\right)$ are determined, and product categories are defined.

Table 2. Initial decision-making matrix with linguistic values 
Table 3. The results of novel integrated Fuzzy FUCOM - fuzzy EDAS model

\begin{tabular}{|c|c|c|c|c|}
\hline & $\widetilde{s p_{i}}$ & $\widetilde{s n_{i}}$ & \multicolumn{2}{|c|}{$\widetilde{n s p_{i}}$} \\
\hline $\mathrm{A}_{1}$ & $(-0.05,0.01,0.03,0.10)$ & $(-0.30,0.04,0.29,0.66)$ & \multicolumn{2}{|c|}{$(-0.06,0.02,0.04,0.13)$} \\
\hline $\mathrm{A}_{2}$ & $(-0.09,0.05,0.12,0.23)$ & $(-0.26,0.08,0.36,0.66)$ & \multicolumn{2}{|c|}{$(-0.12,0.06,0.15,0.29)$} \\
\hline $\mathrm{A}_{3}$ & $(-0.13,0.17,0.26,0.55)$ & $(-0.54,-0.20,-0.07,0.31)$ & \multicolumn{2}{|c|}{$(-0.16,0.20,0.32,0.68)$} \\
\hline \multicolumn{5}{|c|}{$\ldots$} \\
\hline$A_{76}$ & $(-0.08,0.00,0.02,0.09)$ & $(-0.34,0.00,0.21,0.59)$ & \multicolumn{2}{|c|}{$(-0.10,0.00,0.02,0.12)$} \\
\hline $\mathrm{A}_{77}$ & $(-0.08,0.00,0.02,0.09)$ & $(-0.26,0.08,0.36,0.66)$ & \multicolumn{2}{|c|}{$(-0.10,0.00,0.02,0.12)$} \\
\hline $\mathrm{A}_{78}$ & $(-0.13,0.01,0.05,0.20)$ & $(-0.26,0.08,0.36,0.66)$ & \multicolumn{2}{|c|}{$(-0.16,0.01,0.06,0.24)$} \\
\hline & $n s n_{i}$ & $\widetilde{a s_{i}}$ & $k\left(a s_{i}\right)$ & Group \\
\hline $\mathrm{A}_{1}$ & $(-0.36,0.42,0.92,1.62)$ & $(-0.21,0.22,0.48,0.87)$ & 0.338 & $\mathrm{C}$ \\
\hline $\mathrm{A}_{2}$ & $(-0.35,0.26,0.84,1.54)$ & $(-0.24,0.16,0.50,0.91)$ & 0.334 & $\mathrm{C}$ \\
\hline $\mathrm{A}_{3}$ & $(0.36,1.13,1.40,2.09)$ & $(0.10,0.67,0.86,1.39)$ & 0.752 & B \\
\hline \multicolumn{5}{|c|}{$\ldots$} \\
\hline $\mathrm{A}_{76}$ & $(-0.20,0.58,1.00,1.70)$ & $(-0.15,0.29,0.51,0.91)$ & 0.387 & $\mathrm{C}$ \\
\hline $\mathrm{A}_{77}$ & $(-0.35,0.26,0.84,1.54)$ & $(-0.23,0.13,0.43,0.83)$ & 0.292 & $\mathrm{C}$ \\
\hline $\mathrm{A}_{78}$ & $(-0.35,0.26,0.84,1.54)$ & $(-0.26,0.14,0.45,0.89)$ & 0.307 & $\mathrm{C}$ \\
\hline
\end{tabular}

Since it is impossible to show the results for the classification of the whole assortment of inventory, only individual results are shown in Table 3. The product A68, which is in the first place, has the maximum value of 1.751 . The product $A 36$ has a minimum value of 0.027 . The classification of inventory into groups $\mathrm{A}, \mathrm{B}$ and $\mathrm{C}$ is performed in a range according to the following restrictions: group $\mathrm{A}$ all values $>=1.00$, group $\mathrm{B}>=0.50<1.00$, group $\mathrm{C}<0.50$. This classification of inventory is fully in compliance with the limitation presented in $\mathrm{ABC}$ analysis. The total number of products classified in group A is 18 , which is $23.08 \%$. The products of group B account for $26.91 \%$, i.e. a total of 21 products. The largest number of products belongs to group $\mathrm{C}$ and is 39 , which is $50 \%$. Thus, the limitation $\mathrm{A}<\mathrm{B}<\mathrm{C}$ is satisfied.

\section{Sensitivity analysis and discussion}

Since the integrated fuzzy FUCOM - fuzzy EDAS model has been presented for the first time in this research, it is necessary to verify the obtained results and show why the developed model is applicable and better compared to traditional ones. This is particularly important and necessary, as it addresses the sensitive issue, inventory management, which is essentially very rarely viewed as a multi-criteria model. In this section of the paper, a comparison of the developed model with a classical $\mathrm{ABC}$ analysis is performed. It has been created four $\mathrm{ABC}$ analyses which are based on a single-criterion function, taking into account each criterion individually. After that, as another contribution of this research, a comparison with a model also presented for the first time, the fuzzy FUCOM - ABC model, which takes into account all four criteria, but instead of ranking inventory with the fuzzy EDAS method, ABC analysis has been performed taking into account the weights of the criteria obtained with the fuzzy FUCOM method. 
Figure 2 shows a comparative analysis of the developed integrated fuzzy FUCOM - fuzzy EDAS model with $A B C$ analysis based on the following criteria: quantity $(\mathrm{Q})$, unit price (UP), demand (D), annual procurement cost (APC); and fuzzy FUCOM-ABC based on the presence of inventory by categories $\mathrm{A}, \mathrm{B}$ and $\mathrm{C}$.

Figure 2 shows the numerical and percentage value of the product category in the comparative analysis in accordance with the limitation defined (19). In terms of quantity (Q), a great unevenness can be noticed in the classification of inventory since there are only 10 products of category A, while 52 are of category C. In other models, there is a more even share of the amount of products. According to this comparative analysis, the fuzzy FU$\mathrm{COM}$ - fuzzy EDAS model shows the most similarities with the ABC analysis regarding annual procurement cost (APC).

In Figure 3, the trend of product classification into groups can be observed, considering all approaches in sensitivity analysis. The products are presented with codes from the company's annual report. It can be observed that there are significant differences in the classification of inventory by different approaches in sensitivity analysis. Additionally, a detailed classification for each product is shown in Figure 3 where the advantage of the newly developed fuzzy MCDM model can be seen. A detailed inventory structure in relation to all approaches is presented. It can be seen that in the classification of inventory, the developed fuzzy FUCOM - fuzzy EDAS (FFUCOM - FEDAS) model is the best solution since, compared to all the others, it has shared characteristics and the smallest deviations. The developed FFUCOM - FEDAS model compared to all other approaches, FFUCOM - ABC APC - D - UP - Q has one shared feature. FFUCOM - FEDAS - FFUCOM ABC - APC D - UP has three shared products that have the same classification, i.e. have been classified in the same group. FFUCOM - FEDAS - FFUCOM ABC - APC - D has 17 products that have the same product category. FFUCOM - FEDAS - FFUCOM ABC - APC shows that 54 products are in the same category, while most products, $83.33 \%$, i.e. 65 products have a shared category in FFUCOM - FEDAS - FFUCOM ABC, which is understandable given that both models represent a classification of inventory based on a multi-criteria function. Furthermore, comparing the developed model with other individual analyses, it has most shared products (63) with APC. It is important to emphasize that APC contains UP and Q. The created fuzzy model with ABC analysis based on Q has 58 products classified in the same groups, while that number with FFUCOM - FEDAS - D and FFUCOM - FEDAS - UP is 23 and 22, respectively. That it is the best model (FFUCOM - FEDAS) is also indicated by the fact that there is only one product that does not have a shared group with some of the other approaches in the comparative analysis. The FFUCOM - ABC model, which has only two products without shared groups compared to other models, stands out as a very good solution, representing also a contribution of this paper.

Marketing logistics through coordinated and synchronized activities should provide an efficient way to deliver value to the customer. The marketing logistics department, ie the instruments through which it performs business management are customer service, demand forecasting, communication in the distribution channel, inventory control, material management, the process of receiving orders, etc. 


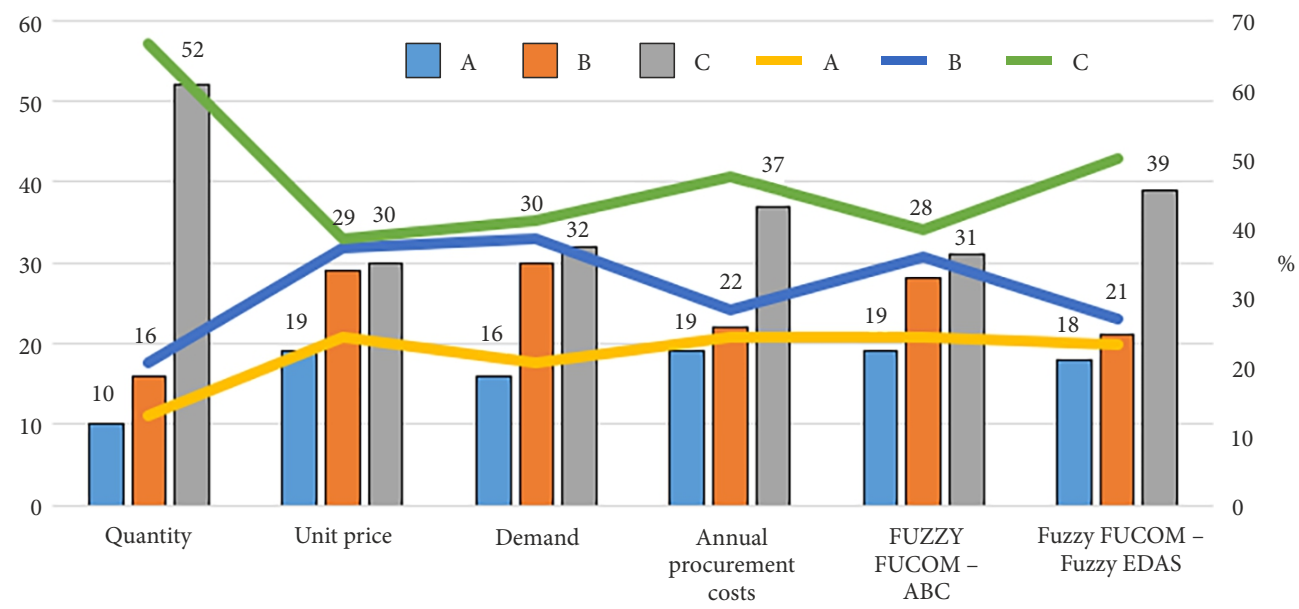

Figure 2. Comparison analysis in terms of inventory presence in groups A, B and C

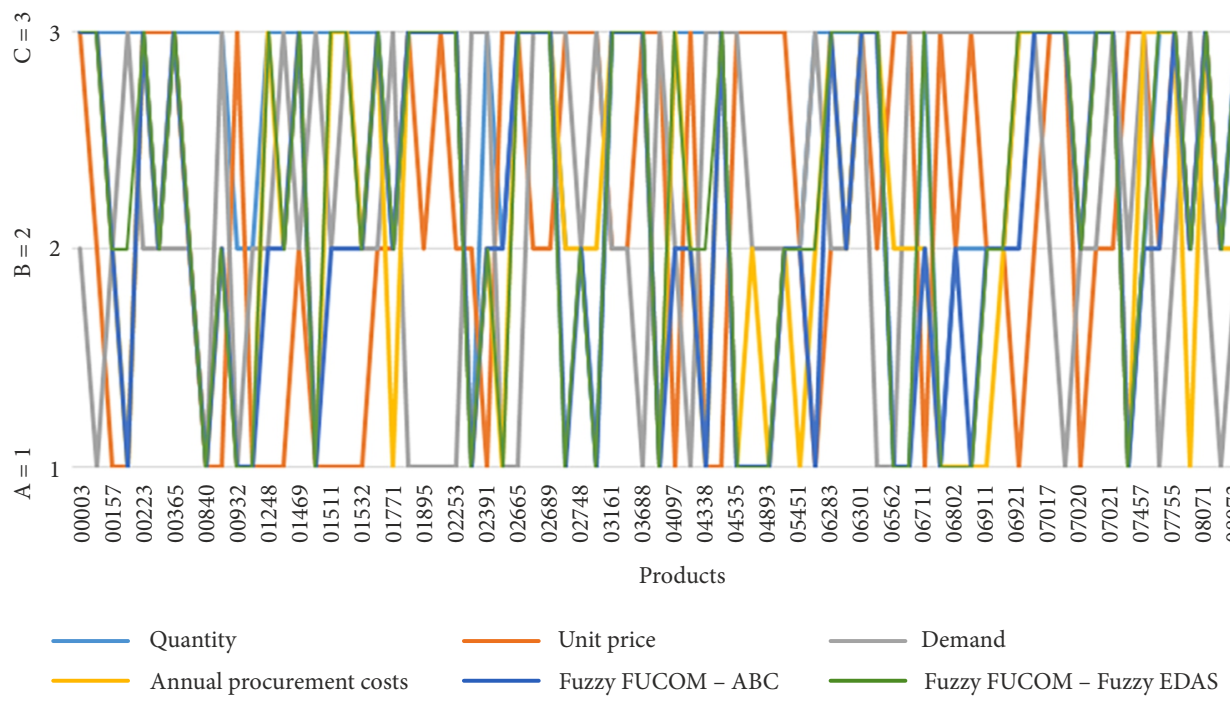

Figure 3. Comparative analysis of fuzzy FUCOM - fuzzy EDAS model with other approaches in terms of inventory classification

The following limitation of the study can be singled out as managerial implications. Fuzzy FUCOM - The Fuzzy EDAS model involves a rather complex mathematical technique, as it relies on fuzzy theory and operations with TFNs. If there is an increase in the number of products or decision-makers in the model, if it is group decision-making, the model becomes even more complicated. However, solving this limitation can be achieved through the development of an application that will automate this process. The authors have created an application in Microsoft Excel through this study. 


\section{Conclusions}

In this paper, two novel integrated fuzzy inventory management models have been developed in order to achieve a more rationalized and economical business. Based on the reports of marketing logistics subsystems and the organization of warehousing systems, multi-phase models of sorting and inventory management have been formed, taking into account the multi-criteria function. Based on the following criteria: quantity, unit price, annual procurement costs and demand, the classification of inventory has been performed primarily with the novel integrated fuzzy FUCOM - fuzzy EDAS model. The developed integrated model has shown exceptional characteristics for solving the problem of inventory classification and management. In this particular case, the classification of inventory into groups A, B and C has been performed in a range according to the following restrictions: group $\mathrm{A}$ all values $>=1.00$, group $\mathrm{B}>=0.50<1.00$, group $\mathrm{C}<0.50$. In addition, it has been developed a novel fuzzy FUCOM - ABC model that can be used to sort inventory for all multi-parameter inputs. The greatest contributions of the research are the newly developed fuzzy models that provide a better insight into inventories, which is causally related to the cost function of the entire company. The developed integrated models have been verified through a comparative analysis with traditional $\mathrm{ABC}$ analysis approaches, taking into account the single-criterion function since they showed significantly better performance.

Future research may relate to the creation of a universal fuzzy MCDM model or a fuzzy MCDM - ABC model treating a larger number of criteria that would be appropriate for a larger number of companies. Moreover, the inclusion of demand factors, but through the definition of variation coefficient, can be one of important parameters for sorting inventories. Additionally, for this purpose can be performed XYZ analysis and created some inventory management policies that include strategies about supply materials. Also, a combination of fuzzy MCDM methods, ABC, and XYZ analysis can be one way of future research for precise inventory management.

\section{Funding}

This research received no external funding.

\section{Author contributions}

Conceptualization, D. V. and D. G.; methodology, Ž. S.; validation, S. T., and P. M.; data curation, S. T. and D. V.; writing-original draft preparation, Ž. S. and D. G.; writing-review and editing, P. M.

\section{Disclosure statement}

The authors declare no conflict of interest. 


\section{References}

Abdolazimi, O., Esfandarani, M. S., \& Shishebori, D. (2020). Design of a supply chain network for determining the optimal number of items at the inventory groups based on ABC analysis: a comparison of exact and meta-heuristic methods. Neural Computing and Applications, 1-16. https://doi.org/10.1007/s00521-020-05428-y

Anthony, P., Behnoee, B., Hassanpour, M., \& Pamucar, D. (2019). Financial performance evaluation of seven Indian chemical companies. Decision Making: Applications in Management and Engineering, 2(2), 81-99. https://doi.org/10.31181/dmame1902021a

Arikan, F., \& Citak, S. (2017). Multiple criteria inventory classification in an electronics firm. International Journal of Information Technology \& Decision Making, 16(02), 315-331. https://doi.org/10.1142/S0219622017500018

Božić, V., \& Aćimović, S. (2014). Marketing logistics. Faculty of Economics, Belgrade.

Cherif, H., \& Ladhari, T. (2016, November). A new hybrid multi-criteria ABC inventory classification model based on differential evolution and Topsis. In International Conference on Hybrid Intelligent Systems (pp. 78-87). Springer. https://doi.org/10.1007/978-3-319-52941-7_9

Chu, C. W., Liang, G. S., \& Liao, C. T. (2008). Controlling inventory by combining ABC analysis and fuzzy classification. Computers \& Industrial Engineering, 55(4), 841-851.

https://doi.org/10.1016/j.cie.2008.03.006

Douissa, M. R., \& Jabeur, K. (2016, January). A new model for multi-criteria ABC inventory classification: PROAFTN method. Procedia Computer Science, 96, 550-559.

https://doi.org/10.1016/j.procs.2016.08.233

Douissa, M. R., \& Jabeur, K. (2020). A non-compensatory classification approach for multi-criteria ABC analysis. Soft Computing, 24(13), 9525-9556. https://doi.org/10.1007/s00500-019-04462-w

Eraslan, E., \& İÇ, Y. T. (2020). An improved decision support system for ABC inventory classification. Evolving Systems, 11, 683-696. https://doi.org/10.1007/s12530-019-09276-7

Erceg, Ž., Starčević, V., Pamučar, D., Mitrović, G., Stević, Ž., \& Žikić, S. (2019). A new model for stock management in order to rationalize costs: ABC-FUCOM-interval rough CoCoSo model. Symmetry, 11(12), 1527. https://doi.org/10.3390/sym11121527

Flores, B. E., \& Whybark, D. C. (1986). Multiple criteria ABC analysis. International Journal of Operations \& Production Management, 6(3), 38-46. https://doi.org/10.1108/eb054765

Hanafi, R., Mardin, F., Asmal, S., Setiawan, I., \& Wijaya, S. (2019, October). Toward a green inventory controlling using the $\mathrm{ABC}$ classification analysis: A case of motorcycle spares parts shop. In IOP Conference Series: Earth and Environmental Science (Vol. 343, No. 1, p. 012012). IOP Publishing. https://doi.org/10.1088/1755-1315/343/1/012012

Ishizaka, A., \& Gordon, M. (2017). MACBETHSort: a multiple criteria decision aid procedure for sorting strategic products. Journal of the Operational Research Society, 68(1), 53-61. https://doi.org/10.1057/s41274-016-0002-9

Ishizaka, A., Lolli, F., Balugani, E., Cavallieri, R., \& Gamberini, R. (2018). DEASort: Assigning items with data envelopment analysis in ABC classes. International Journal of Production Economics, 199, 7-15. https://doi.org/10.1016/j.ijpe.2018.02.007

Kartal, H., Oztekin, A., Gunasekaran, A., \& Cebi, F. (2016). An integrated decision analytic framework of machine learning with multi-criteria decision making for multi-attribute inventory classification. Computers \& Industrial Engineering, 101, 599-613. https://doi.org/10.1016/j.cie.2016.06.004

Keller, K. L., \& Kotler, P. (2006). Marketing management. Data status. 
Keshavarz Ghorabaee, M., Zavadskas, E. K., Amiri, M., \& Turskis, Z. (2016). Extended EDAS method for fuzzy multi-criteria decision-making: an application to supplier selection. International Journal of Computers Communications \& Control, 11(3), 358-371. https://doi.org/10.15837/ijccc.2016.3.2557

Keshavarz Ghorabaee, M., Zavadskas, E. K., Olfat, L., \& Turskis, Z. (2015). Multi-criteria inventory classification using a new method of evaluation based on distance from average solution (EDAS). Informatica, 26(3), 435-451. https://doi.org/10.15388/Informatica.2015.57

Kheybari, S., Naji, S. A., Rezaie, F. M., \& Salehpour, R. (2019). ABC classification according to Pareto's principle: a hybrid methodology. Opsearch, 56(2), 539-562. https://doi.org/10.1007/s12597-019-00365-4

Kubasakova, I., Poliakova, B., \& Kubanova, J. (2015). ABC analysis in the manufacturing company. In Applied mechanics and materials (Vol. 803, pp. 33-39). Trans Tech Publications Ltd. https://doi.org/10.4028/www.scientific.net/AMM.803.33

Liu, J., Liao, X., Zhao, W., \& Yang, N. (2016). A classification approach based on the outranking model for multiple criteria ABC analysis. Omega, 61, 19-34. https://doi.org/10.1016/j.omega.2015.07.004

Mallick, B., Das, S., \& Sarkar, B. (2019). Application of the modified similarity-based method for multicriteria inventory classification. Decision Science Letters, 8(4), 445-470. https://doi.org/10.5267/j.dsl.2019.5.001

Oliveira, F., \& Vaz, C. B. (2017). Spare parts inventory management using quantitative and qualitative classification. In Engineering Systems and Networks (pp. 233-241). Springer. https://doi.org/10.1007/978-3-319-45748-2_25

Pamučar, D., \& Ecer, F. (2020). Prioritizing the weights of the evaluation criteria under fuzziness: the fuzzy Full Consistency Method-FUCOM-F. Facta Universitatis, Series: Mechanical Engineering, 18(3), 419-437. https://doi.org/10.22190/FUME200602034P

Pamučar, D., Deveci, M., Canıtez, F., \& Božanić, D. (2020). A fuzzy Full Consistency Method-DombiBonferroni model for prioritizing transportation demand management measures. Applied Soft Computing, 87, 105952. https://doi.org/10.1016/j.asoc.2019.105952

Stević, Ž., Stjepanović, Ž., Božičković, Z., Das, D. K., \& Stanujkić, D. (2018a). Assessment of conditions for implementing information technology in a warehouse system: A novel fuzzy piprecia method. Symmetry, 10(11), 586. https://doi.org/10.3390/sym10110586

Stević, Ž., Vasiljević, M., Zavadskas, E. K., Sremac, S., \& Turskis, Z. (2018b). Selection of carpenter manufacturer using fuzzy EDAS method. Engineering Economics, 29(3), 281-290. https://doi.org/10.5755/j01.ee.29.3.16818

ten Hompel, M., \& Schmidt, T. (2008). Warehouse management. Springer. https://doi.org/10.1007/978-3-540-74876-2

van den Berg, J. P., \& Zijm, W. H. (1999). Models for warehouse management: Classification and examples. International Journal of Production Economics, 59(1-3), 519-528.

https://doi.org/10.1016/S0925-5273(98)00114-5 